\title{
Use and Impact of Information Technology in the African Construction Industry: a preliminary survey from Benin
}

\author{
Conrad Boton ${ }^{1}$ \\ ${ }^{1}$ École de Technologie Supérieure, 1100, rue Notre-Dame Ouest, Montréal, Canada \\ conrad.boton@etsmtl.ca
}

\begin{abstract}
This paper presents the results of a preliminary survey in Benin, a West African country. The aim of the study is to estimate the use and the impact of IT in the Benin construction industry. To ensure that the results can be compared to other related surveys, this study used the "IT Barometer" questionnaire. The results show that while office and design software are widely used, Internet-based solutions for the construction industry seem less well-known. In addition, very few firms have an IT strategy and the proportion of management activities with IT support remains low. The respondents seem very optimistic regarding the role of IT in their organizations but most of them think that the constant need to update and the cost of investment in IT are the main barriers to their implementation.
\end{abstract}

Keywords: Architecture Engineering Construction, Africa, Benin, Survey, IT Barometer.

\section{Introduction}

Information technology (IT) has dramatically changed the architecture, engineering and construction (AEC) industry, especially by enabling technological prowess hitherto impossible and increasing efficiency, but also, sometimes changing the paradigm of construction projects' organization. Several research studies have focused on the adoption of these technologies and their real impact in the sector [1-3]. It is indeed interesting to know the level and the conditions of their use in order to better assist practitioners in improving their IT strategies and to provide reliable decision-making tools.

However, while several investigations have been conducted to accurately assess the impact of IT in construction in many parts of the world, very few of these studies have focused on the African continent. Meanwhile, African countries are (generally) developing, with the construction industry more and more occupying an important place in their economies. And, as in all emerging countries, IT application faces many specific constraints, not only in terms of infrastructure but also from cultural and economic differences [4]. This applies to Benin, a West African country where authorities decided years ago to focus on major construction works in order to contribute to the revival of the economy. While some studies [5] have highlighted continuing problems in the management of construction projects (document management, coordination, etc.), to date a 
few studies have been conducted to assess the use and impact of these technologies in the sector in order to adapt solutions to stakeholders needs.

Using the well-known "IT Barometer" questionnaire [2] already used in several countries, a survey was conducted on a sample of Benin construction industry practitioners. This paper presents and discusses its results.

\section{Related works and context}

\subsection{Related works and the origin of the survey}

Information Technology (IT) can be defined as "the use of electronic machines and programs for the processing, storage, transfer and presentation of information" [6]. Mélèse [7] defined information, with material and energy, as "the third fundamental component of socio-technical systems, which are companies," and estimated that a central problem of public and private organizations is related to information management. The formats commonly used to represent information in construction are text documents, 2D and 3D drawings, schedules in bar chart and other formats, various diagrams and charts, tables, etc. IT has dramatically improved how interdisciplinary construction project work is described and documented [8].

Ahmad et al. [9] summarize the construction industry characteristics, arguing that processes are dynamic and based on the complex interrelationships among the various participating entities, wherein team-work is necessary to successfully construct a facility, operations are people-intensive and cannot be completely automated or mechanized. The solutions of construction project problems are highly dependent upon the experience and judgment of professionals and involve uncertainties. These barriers to applying IT in AEC make it a challenging and interesting problem to produce an inventory of the use and the impact of IT in the industry. Studies have been done on the construction industries of Canada [10], Hong Kong [1], Denmark, Sweden and Finland $[2,3]$, Luxembourg [11] and other countries to evaluate the use and the impact of IT in construction.

In Africa, some significant research has been conducted without specifically using the IT Barometer survey questionnaire. The 'IT health check' has been applied to the South African construction sector, and the use of IT for architectural practices have been investigated in Cape Province [12]. Molony [13] tried to estimate the role of mobile phones in the informal construction sector with the case of Dar es Salaam in Tanzania. In 2010, Musa [14] evaluated the impact of Information and Communications Technology (ICT) on the quality of the surveying services in Nigeria, and Oyediran \& Akintola [15] realized a survey of the state of the art of e-tendering in Nigeria. More recently, some BIM surveys have also been conducted [16-18]. Even if these studies are very interesting, they do not seem up to the task of estimating the real use of IT in the African construction industry, according to the definition of IT above. The construction sector is becoming more and more significant for African countries that are generally deemed developing nations; therefore it is important to evaluate the use and 
the contribution of IT in the sector to better guide regulators, decision makers and practitioners. It is also important to make it possible to compare studies from one country to another and over time. In this context, using the IT barometer questionnaire appears to be especially worthwhile.

\subsection{The context of the Benin construction sector}

The Republic of Benin is a 112,622 sq. km country in West Africa. With a population of approximately 10 million inhabitants, it is bounded in the north by Niger, northwest by Burkina Faso, south by the Atlantic Ocean, east by Nigeria and west by Togo.

As in many African countries, the development of the construction sector has become an important challenge for Benin. Indeed, to contribute to boosting investments (a major axis for the country's development), a policy of encouraging major construction projects is being implemented. The government has made the AEC sector a priority. In only a few months, several major projects were launched in 2010 with the financial contribution of donors and whose budgets were estimated at 2.3 billion U.S. dollars over five years [19]. The construction sector in Benin is thus being driven both by government building programs and private demand [20]. Benin small and medium-sized enterprises (SME) are involved in construction as contractors, engineering companies or architectural firms. The two largest project management support agencies are AGETUR and AGETIP-BENIN. Construction industry actors are grouped into professional organizations such as the National Order of Architects and Planners (ONAUB), the Association of Building Materials Importers (ANIMAC) and the National Association of Contractors (ANEC).

On the scientific side, a series of international conferences titled West Africa Built Environment Research (WABER ${ }^{1}$ ) takes place every year, and so since its creation in 2008. Its increasing success shows the real need for scientific support of the construction sector in the region.

\subsection{The methodology and the respondents' profiles}

As stated above, the "IT Barometer" questionnaire was used. This questionnaire was first translated into French which is the official language in Benin. A form containing the questions was sent to a statistical sample of 75 firms across the country, using Google Documents. Practitioners could then fill in the questionnaire online. A peculiarity of the survey lies in its online aspect. This of course introduces a bias to the results, since all the respondents are expected to use the Internet and thus already be familiar with IT. The results presented below should therefore be viewed with this perspective. However, despite this bias, they still provide a good overview of the situation among those firms that are supposed to be familiar with IT. Note that a second phase of the survey is planned in order to address the bias.

A total of 17 firms responded to the survey. Figure 1 shows the respondents' profiles according to their activities. Twenty-three percent (23\%) of the respondents are based in

\footnotetext{
${ }^{1}$ www.waberconference.com
} 
architecture firms, twenty-nine percent (29\%) are from engineering firms, twenty-four percent $(24 \%)$ are contractors and twenty-four percent $(24 \%)$ are owners.

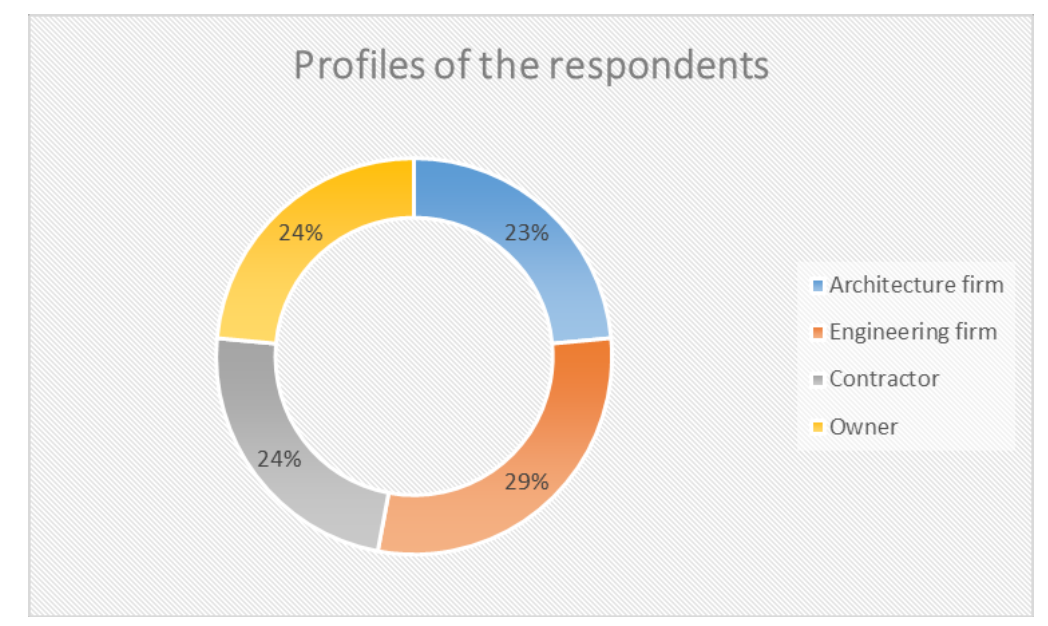

Fig. 1. Profiles of the respondents.

\section{Results and discussion}

\subsection{Main results}

Despite the bias presented above, some interesting lessons can be learned from this preliminary survey. The first one is related to the use of IT tools in the daily work of the surveyed firms (See Fig. 2). All of them know and use word processing, spreadsheet and e-mail applications. More than seventy percent (70\%) claim they use IT to support technical design activities, while planning activities are performed with IT support for almost sixty percent $(60 \%)$ of the respondents. The activities related to administration, costs and budgets and databases are said to be performed with IT applications by more than forty percent (40\%). Facility management appears to be the activity that is performed the least with IT applications (a little more than 10\%). 


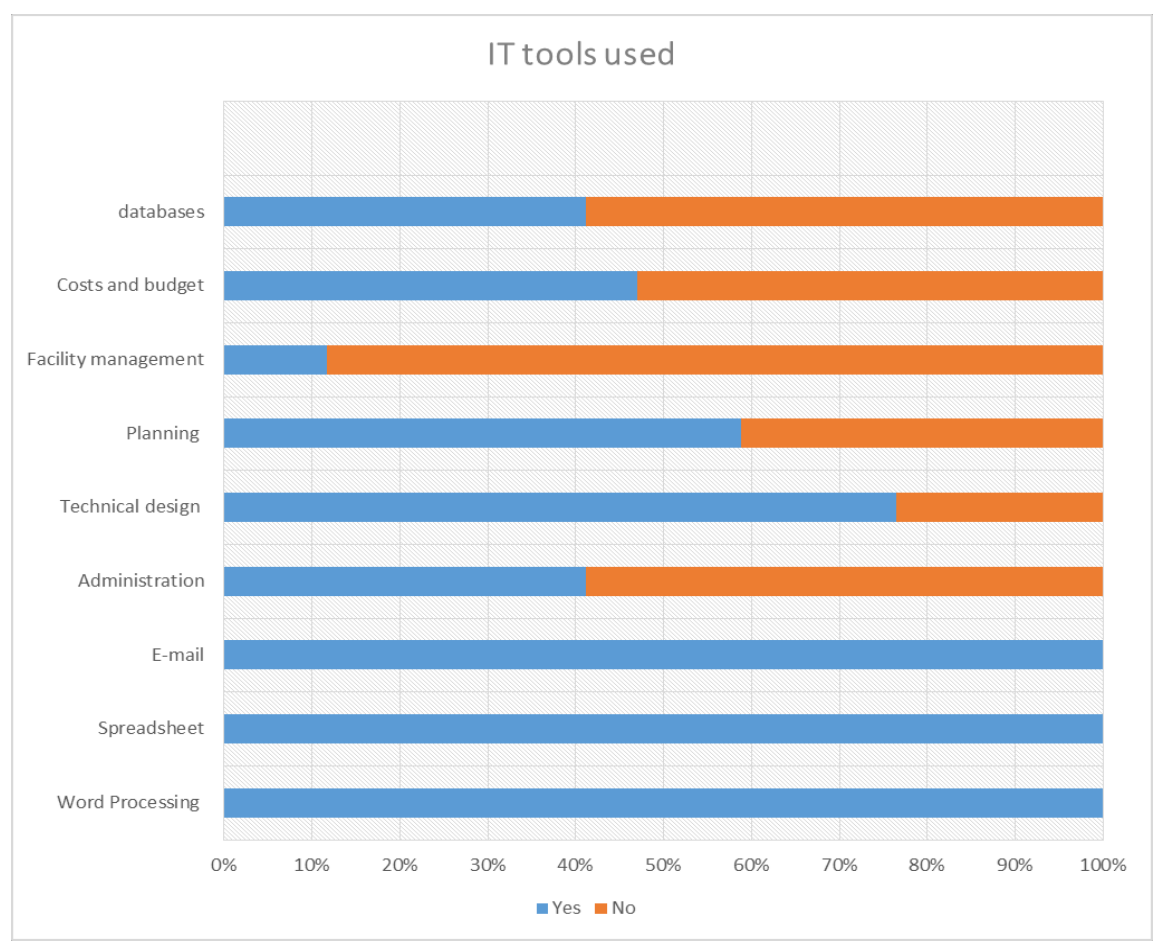

Fig. 2. IT applications used to perform daily activities.

Figure 3 gives the percentages of the degrees to which management activities are performed with the support of IT applications. It appears that all activities are more or less done with computers, but the proportions remain low. 


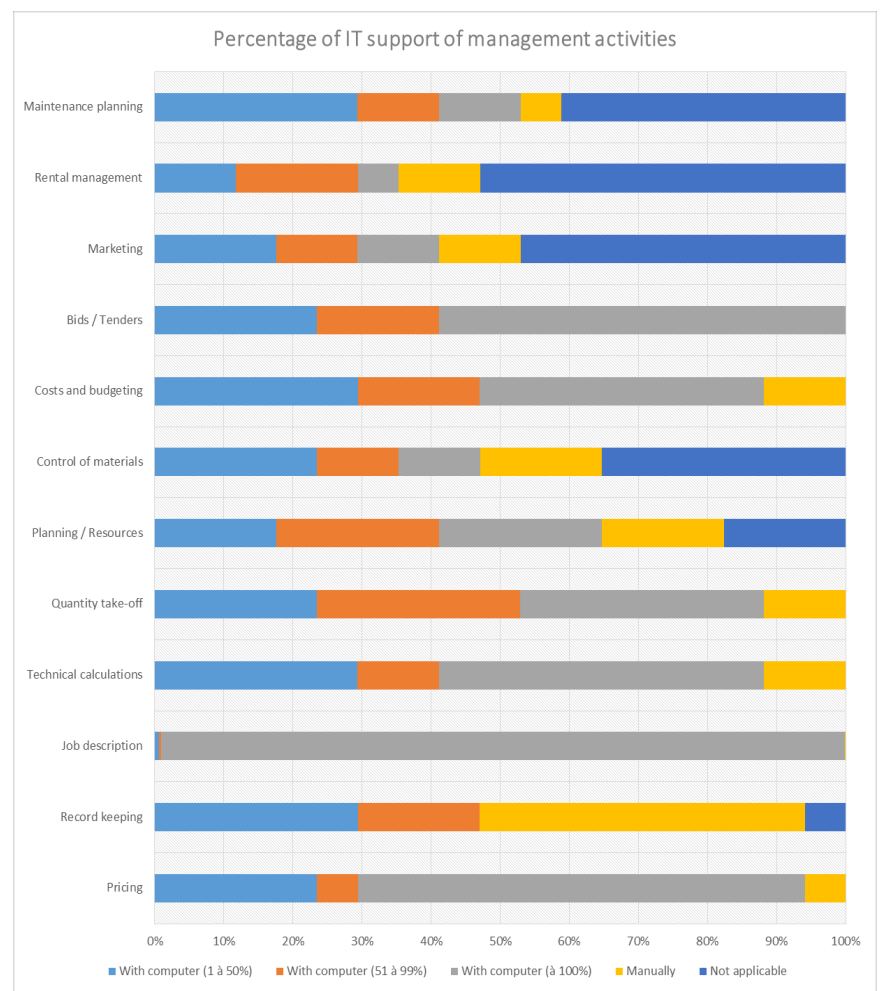

Fig. 3. Proportion of IT support for management activities.

Regarding the existence of an IT strategy, it appears that such a strategy does not exist in the majority of the firms. Forty-seven percent (47\%) of the firms clearly indicated that they do not have one. Twenty-four percent $(24 \%)$ of the respondents say they have one, but only in oral form. Eighteen percent (18\%) of the respondents did not know and it can reasonably be argued that they do not have an IT strategy. Only twelve percent $(12 \%)$ of the firms indicated that they have an IT strategy in written form.

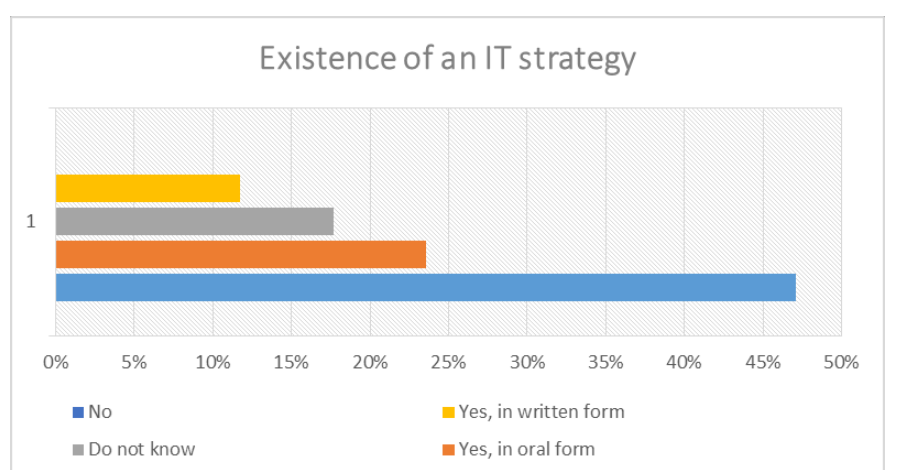

Fig. 4. Existence of an IT strategy. 
Another interesting indication of their integration of IT is the existence of a website to promote their firms' activities. Only eighteen percent (18\%) of the firms declared they have a website. Seventy-six percent $(76 \%)$ do not have a website but think that it is a desired objective. Six percent $(6 \%)$ declared that they do not need a website.

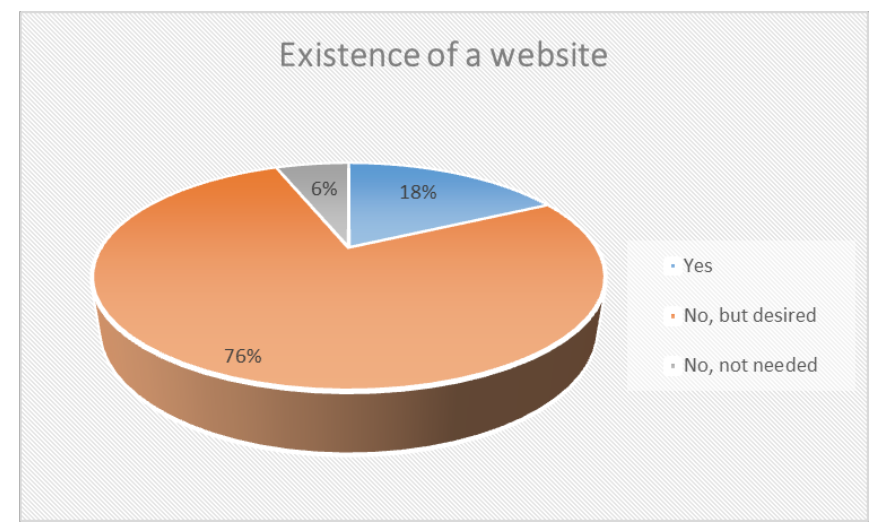

Fig. 5. Existence of a website for the firm.

Overall, the respondents seem very optimistic regarding the role of IT in their organizations, but most of them think that the constant need to update and the costs of investments in IT are the main barriers to their implementation. The survey also reveals that firms are planning to invest more in project management solutions in the near future. Customer demand and efficiency in the technical work are the reasons most often cited for this investment decision.

\section{Conclusion}

The construction industry is becoming more and more important in African countries that are mostly developing nations. To help decision makers and practitioners in their investment choices in information technology, it is important to have a good idea of the use of these technologies, their impact and the needs for innovation from the practitioners' perspective. This paper presents the results of a survey conducted in Benin, using the "IT Barometer" questionnaire.

It appears from this study that while office and design software are widely used, Internet-based solutions are less well-known. In addition, very few firms have an IT strategy and the overall proportion of IT support for management activities remains low. Moreover, the results of this study show that it would be worthwhile to perform the same type of analysis on other African countries in order to establish a mapping of IT practices in the African construction industry. It must be noted that the online nature of the survey introduces a bias to the results, since all the respondents are expected to use the Internet and thus are (to some degree) familiar with IT. 


\section{References}

1. K. Futcher and S. Rowlinson, "IT survey within the construction industry of Hong Kong," in 8th International Conference on Durability of Building Materials and Components, 1999, vol. 4, pp. 2306-2315.

2. R. Howard, A. Kiviniemi, and O. Samuelson, "Surveys of IT in the construction industry and experience of the IT barometer in Scandinavia," vol. 3, no. November, pp. 45-56, 1998.

3. O. Samuelson, "The IT-Barometer-A decade's development of IT use in the Swedish construction sector," ITcon, vol. 13, no. December 2007, pp. 1-19, 2008.

4. S. Scheer, S. Leusin de Amorim, E. Santos, R. Ferreira, and A. Caron, "The scenario and trends in the Brazilian it construction applications' experience," J. Inf. Technol. Constr., vol. 12, pp. 193-206, 2007.

5. C. Boton, "Gestion de l'information au sein des projets de construction: De l'expérience luxembourgeoise à la propositiond'un modèle de système d'information pour l'Afrique," Université Senghor d'Alexandrie, 2009.

6. B. C. Björk, "Information Technology in Construction-domain definition and research issues,” Int. J. Comput. Integr. Des. Constr., vol. 1, no. 1, pp. 1-16, 1999.

7. J. Mélèse, Approches systémiques des organisations: vers l'entreprise à complexité humaine. Les Editions d'Organisation, 1990.

8. M. Fischer and J. Kunz, "The scope and role of information technology in construction," in Proceedings-Japan Society of Civil Engineers, 2004, no. February, pp. 1-32.

9. I. U. Ahmad, J. S. Russell, and A. Abou-Zeid, "Information technology (IT) and integration in the construction industry.," Constr. Manag. Econ., vol. 13, pp. 163-171, 1995.

10. H. Rivard, "A survey on the impact of information technology on the Canadian architecture, engineering and construction industry," Electron. J. Inf. Technol. Constr., vol. 5, no. February, pp. 37-56, 2000.

11. S. Kubicki and C. Boton, "IT Barometer Survey in Luxembourg: First Results to Understand IT Innovation in Construction Sector," in Computing in Civil and Building Engineering, 2014, pp. 179-186.

12. A. A. Arif and A. Karam, "Architectural practices and their use of IT in the Western Cape Province, South Africa," J. Inf. Technol. Constr., vol. 6, no. September, pp. 17-34, 2001.

13. T. Molony, "The Role of Mobile Phones in Tanzania's Informal Construction Sector: The Case of Dar es Salaam," Urban Forum, vol. 19, no. 2, pp. 175-186, Apr. 2008.

14. N. A. Musa, "A Study of the Impact of Information and Communications Technology (ICT) on the Quality of Quantity Surveying Services in Nigeria.," Electron. J. Inf. Syst. Dev. Ctries., vol. 42, 2010.

15. O. S. Oyediran and A. A. Akintola, "A survey of the state of the art of e-tendering in nigeria," J. Inf. Technol. Constr., vol. 16, no. March, pp. 557-576, 2011.

16. W. Jung and G. Lee, "The Status of BIM Adoption on Six Continents," Int. J. Civil, Struct. Constr. Archit. Eng., vol. 9, no. 5, pp. 406-410, 2015.

17. F. H. Abanda, M. B. Manjia, C. Pettang, J. H. M. Tah, and G. E. Nkeng, "Building Information Modelling in Cameroon: Overcoming Existing Challenges," Int. J. 3-D Inf. Model., vol. 3 , no. 4, 2014.

18. C. Wang, "Assessment of BIM implementation among MEP firms in Nigeria," Int. J. Adv. Appl. Sci., vol. 4, no. 3, 2015.

19. United Nations, "Guide de l'investissement au Bénin. Opportunités et conditions," New York \& Genève, 2010.

20. I\&P, “Libérer l'esprit d'entreprise en Afrique. Rapport d'activité 2009-2010,” Paris, France, 2010. 